\title{
Um novo tempo nas telas brasileiras
}

Resumo: O especialista em comunicação André Barbosa Filho, assessor especial do Gabinete Civil da Presidência da República para assuntos relacionados a políticas públicas de comunicação, comenta o impacto da implantação, no Brasil, de novas tecnologias ligadas aos sistemas de banda larga e de televisão digital, além de comentar as prioridades das políticas públicas relativas às mudanças sociais e tecnológicas trazidas por essas inovações.

Palavras-chave: televisão digital, rádio, telecomunicações, interatividade, banda larga.
Abstract: The communication specialist André Barbosa Filho, special adviser at the Republic Presidency Civil Office on matters related to the communication public policy, comments the implementation impact, in Brazil, of new technologies linked to broadband and digital television systems besides commenting the public policies priorities related to the social and technological changes brought by these innovations.

Keywords: digital television, radio, telecommunications, interactivity, broadband.

O que podemos esperar da nova era das comunicações, regida pela tecnologia digital? O trabalho de André Barbosa Filho, assessor especial do Gabinete Civil da Presidência da República para assuntos relacionados a políticas públicas de comunicação, está diretamente ligado a essa discussão. Tendo dedicado sua carreira ao campo da comunicação, Barbosa já estudou e vivenciou diversas revoluções tecnológicas. Como produtor, diretor e coordenador de programação em TV e rádio, passou por emissoras como Cultura, Globo, USP-FM e Jovem Pan. O gosto pela atividade comunicacional o levou também à área acadêmica, tornando-se mestre em Comunicação Científica e Tecnológica e doutor em Ciências da Comunicação. Além de professor de radiojornalismo, foi ainda chefe do departamento de Comunicação Social da Universidade Metodista de São Paulo. Hoje, acompanha de perto a atuação estratégica do governo brasileiro dentro das presentes $e$ futuras mudanças nos meios digitais, assim como suas implicações e benefícios sociais. Nesta entrevista, ele fala sobre os avanços do país em tais áreas e as expectativas geradas por este novo tempo das comunicações no Brasil.

Por Juliana Winkel

C\&E: O que podemos esperar da implantação da TV Digital e da TV Pública no Brasil? $O$ senhor acredita que haverá real incentivo à abordagem de temas ligados à educação, cultura e cidadania?

André Barbosa: Podemos esperar muito, porém essa implantação é incipiente ainda por uma série de razões. A mudança tecnológica de um instrumento como a televisão merece tratamento diferenciado, já que ela tem $96 \%$ da cobertura dos domicílios do Brasil, contra 27\% da internet, por exemplo. Essa mudança tem um papel estratégico para o país, na medida em que pode representar a 
comunicação \& educação • Ano XV • número 3 • set/dez 2010

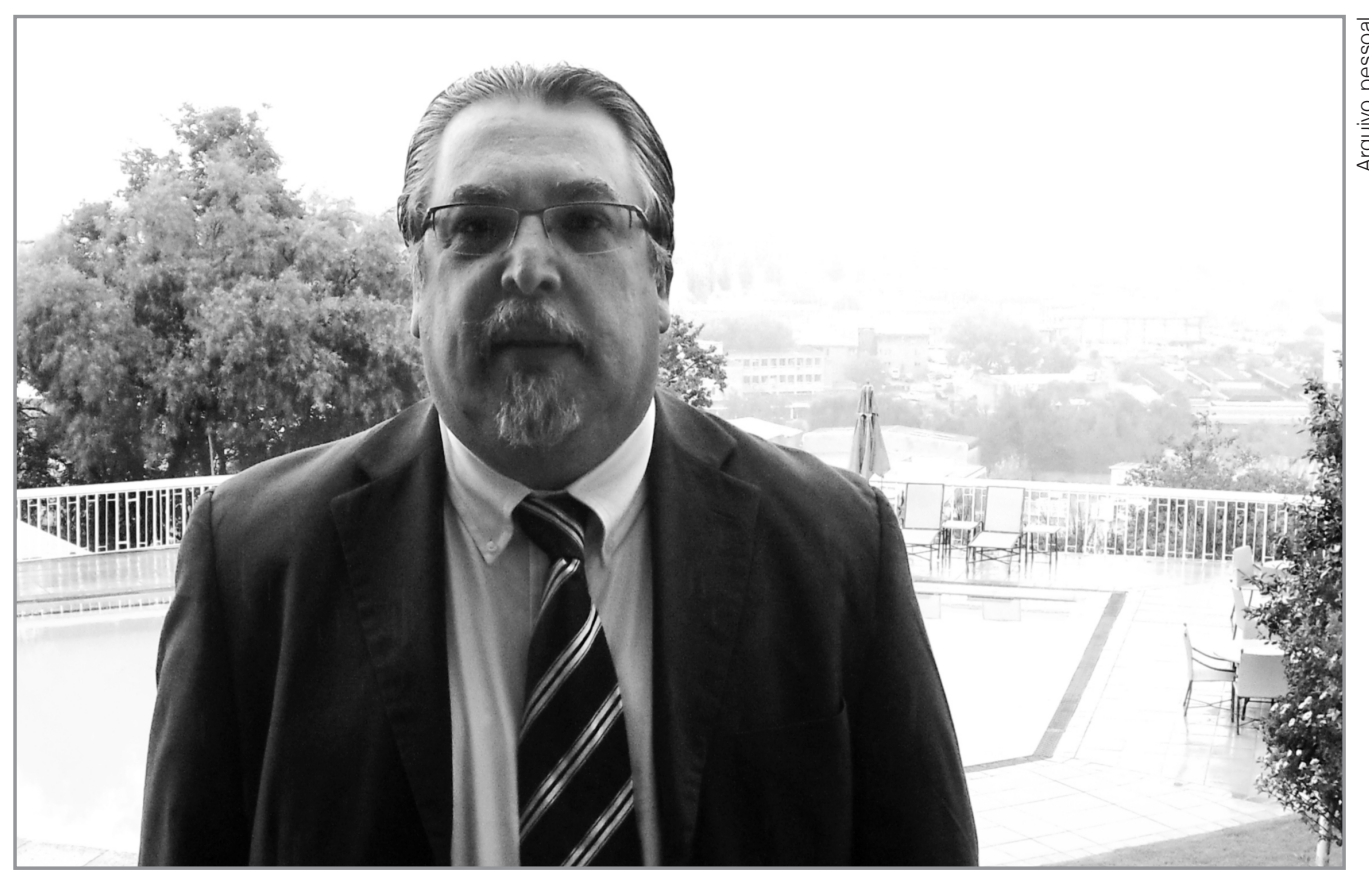

Segundo o assessor André Barbosa, a interatividade, alta definição, mobilidade e a portabilidade concorreram para que o Brasil adotasse o sistema ISDB para a implantação da TV Digital no país.

oferta de serviços públicos pela televisão, como saúde e educação a distância - coisas que a internet também faz, mas que, infelizmente, ainda não temos cobertura suficiente para oferecer.

Já temos tecnologia disponível e todos os elementos estão dispostos a fazer essa mudança: o elemento industrial, por meio de empresas de equipamentos de recepção, transmissão e softwares; a academia, com suas pesquisas e avanços; e o governo, por meio do incentivo à inovação e de políticas de Estado para a implementação das novas tecnologias - inclusive, via acordos internacionais, já que estamos entrando nisso ao lado de vários países do mundo. Estamos agora definindo como percorrer essa trajetória de mudança.

C\&E: Quais as inovações fundamentais em termos de conteúdo, e de que forma a audiência poderá interagir com ele?

André Barbosa: O sistema tecnológico que adotamos se diferencia, justamente, por ter a característica marcante da interatividade. Enquanto o sistema desenvolvido nos Estados Unidos, ATSC, tem como prioridade apresentar melhor qualidade de imagem e som através da alta definição, outros sistemas, como na Europa, possibilitam dividir a programação no que chamamos de modulação hierárquica, transmitindo vários programas num mesmo canal. Nosso caso, porém, é o de procurar usar a televisão com tudo que ela tem de melhor, até porque chegamos depois dos outros e temos a experiência deles para aprender. Então, trabalhamos principalmente quatro questões: a alta definição; a mobilidade, porque temos muitos telespectadores que não ficam apenas diante de televisões fixas, mas também em ônibus e outros veículos; a portabilidade, 


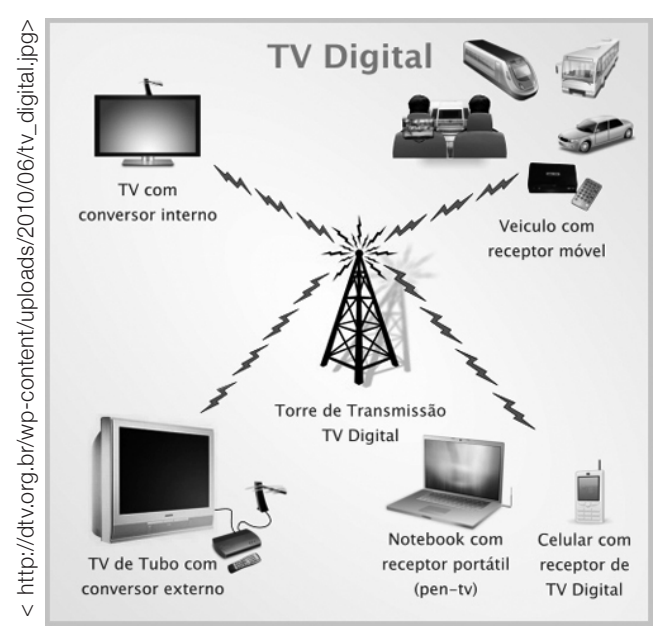

A TV Digital pelo sistema ISDB. possibilitada de forma única pelo sistema ISDB* $^{*}$ (Integrated Services Digital Broadcasting), que permite que se receba a televisão digital de graça no celular. Os outros sistemas transmitem também para celulares, mas fazem isso via rede telefônica, ao contrário deste, que prevê a transmissão direta para esse tipo de aparelho. E temos a quarta questão, que é a interatividade. Esse sistema permite a resposta da população ao estímulo do produtor através da interatividade local, por meio de um aparelho conectado ao próprio televisor e chamado conversor Set Top Box (conversor digital). Ele torna possível acessar, a qualquer hora, uma série de informações ao lado da informação principal, que é o próprio programa. A escalação do time de um jogo de futebol, por exemplo, está lá, bem como o resultado desses mesmos times no ano anterior. E até aplicações mais complexas, como VTs exibidos no passado, podem estar lá.

Isso é interatividade local. A interatividade mais ampla sobre a qual estamos discutindo, porém, é a interatividade plena, e precisa ser construída não apenas com a transmissão, mas também por meio de um sinal de retorno que vá do telespectador à emissora que enviou a mensagem. Com isso, sim, será possível oferecer produtos públicos, como educação a distância com participação real

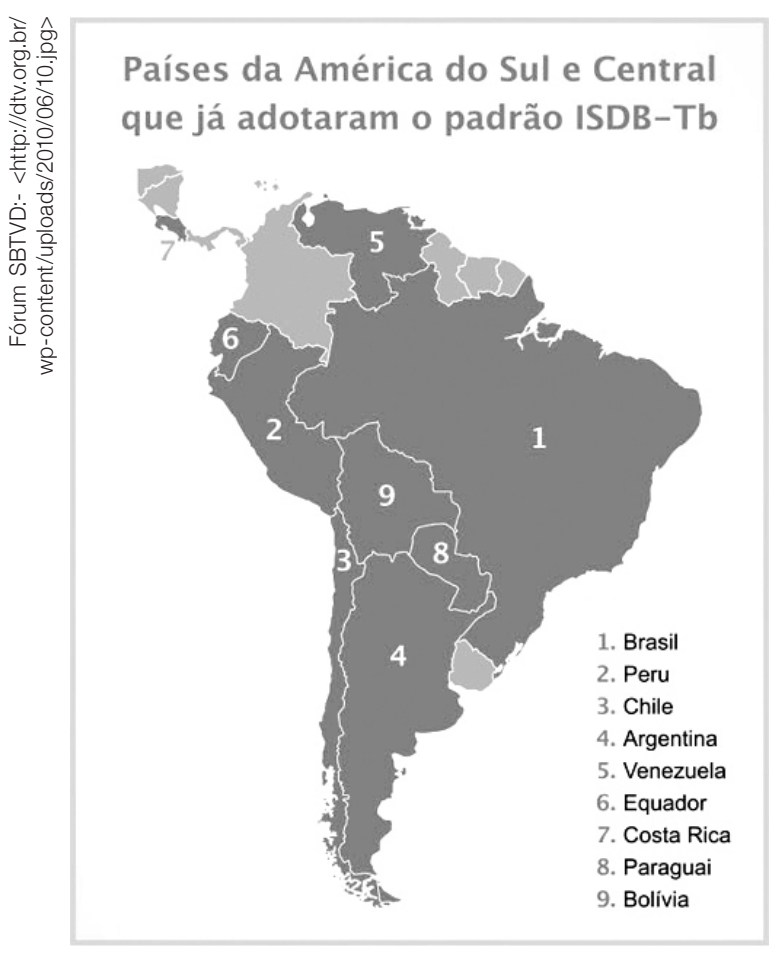
do telespectador. Hoje já se pode acessar bancos e serviços públicos em geral que não necessitem de intervenção maior. Mas a possibilidade individualizada de participar, com interatividade total, ainda é um produto incipiente. Temos muito a caminhar, mas também muitas oportunidades a realizar. E as áreas de software, principalmente, terão um espaço enorme para crescer. É possível que no futuro, por exemplo, a televisão migre para uma tela única que reúna tudo, e que as empresas já estão produzindo - o chamado broadband TV. Mas essa convergência é muito mais fácil de acontecer no primeiro mundo, onde as pessoas podem pagar pelo

* ISDB-TB é o acrônimo para Integrated Services Digital Broadcasting Terrestrial (Sistema Integrado de Radiodifusão Digital Brasileiro), transmitido por ondas terrestres, ou seja, não é nem a cabo nem via satélite. Foi desenvolvido no Japão e o Brasil o adotou com algumas alterações. N.E. 
comunicação \& educação • Ano XV • número 3 • set/dez 2010

“ Em maio de 2010, uma comitiva do governo brasileiro apresentou o seu padrão de televisão digital, desenvolvido a partir de base japonesa, a diversos países da África - que atualmente reveem sua opção inicia pelo sistema de transmissão europeu. $O$ sistema japonês, com inovações tecnológicas brasileiras, já foi também adotado por Argentina, Chile, Peru e Venezuela. N.E.

1. IPTV - Sistema de transmissão de sinais televisivos que utiliza o protocolo IP, conexão estabelecida entre duas ou mais máquinas em rede, como meio de encaminhamento de conteúdo.

** O termo streaming significa fluxo ou, mais especificamente, fluxo de mídia. Trata-se de uma maneira de distribuição de informação multimídia em uma rede pela utilização de pacotes. Esta tecnologia é uma das mais utilizadas para trafegar conteúdo multimídia através da rede mundial de computadores. N.E. serviço de telecomunicações, do que neste nosso enorme terceiro mundo, do qual fazem parte América, Ásia e África, com 4,5 bilhões de pessoas que não podem comprar serviços - e que, portanto, precisam ter uma televisão com todo o benefício de estar no mundo digital sem ter que pagar por ele, ou pelo menos por parte da informação transmitida. Essa é uma questão fundamental - e o Brasil, com a escolha que fez pelo sistema ISDB e suas quantificações específicas, criou um ambiente tecnológico totalmente diferenciado, permitindo que informações vindas de diferentes mídias possam ir para a tela e liberando o acesso também a outras plataformas, como a web. Isso faz com que sejamos competitivos diante dos europeus, dos americanos, dos chineses, e consigamos as vitórias que estamos tendo na África e na América Latina*.

C\&E: Como você vê a receptividade da população brasileira a essas mudanças? André Barbosa: Vou responder a essa pergunta lançando uma reflexão, relativa a um ponto de vista pessoal. Eu acredito que o mundo está caminhando para a convergência tecnológica, que passa obrigatoriamente pela banda larga e pela internet. Então o que se espera é que essas tecnologias, que permitem a participação mais intensa e interativa do usuário, tendam a oferecer produtos e serviços pagos. O Internet Protocol Television, IPTV ${ }^{1}$, por exemplo, deverá ser oferecido mediante a cobrança do sinal que se recebe. Isso é legítimo: existe um serviço, as pessoas querem uma informação diferenciada, então vão comprá-la. Mas no mundo em que nós vivemos não há só gente com dinheiro. Também há quem precisa ganhar dinheiro, mas não tem como pagar por determinados acessos. Então é necessária uma política social mais aberta, que não favoreça só o desenvolvimento industrial, fundamental para que tudo isso aconteça, mas também as camadas de população que não têm recursos e que precisam desses artefatos e desse acesso para poder melhorar sua qualidade de vida.

Por isso, acho que a televisão não vai sucumbir à banda larga e ao IPTV. Ela deve adaptar-se a essa realidade digital, oferecendo, na medida do possível, serviços interativos condizentes com a complexidade tecnológica que estamos vivendo, estabelecendo convergência com as demais plataformas e tecnologias digitais. Na minha visão, a televisão tem algumas características imbatíveis entre elas a simultaneidade. Ela possibilita que eu veja uma informação a que muitas pessoas em rede estão assistindo: um jogo de futebol, o Jornal Nacional, a novela das oito ou um programa de debates. A simultaneidade significa o seguinte: se você sabe com antecedência e se existe uma relação de fidelidade, que é o que a televisão cultua com o seu telespectador, você vai acompanhar aquele programa junto com outras pessoas dentro do mesmo ambiente, não só na sua casa, mas na própria sociedade. Esse programa será fruto de discussão no outro dia. Ninguém vai entrar na internet para ver o jogo do Brasil na Copa do Mundo. Vão buscar a televisão em alta definição, com qualidade, cheia de informação.

Alguém pode dizer que a internet vai caminhar para isso. Mas ela ainda não tem a mesma capacidade de transmitir o streaming ${ }^{*}$, por exemplo, que a televisão proporciona, até pela própria característica da tecnologia empregada 
Um novo tempo nas telas brasileiras - Juliana Winkel

por uma e por outra. A televisão permite que a informação repercuta na sociedade de forma imediata. Em segundo lugar, existe também a possibilidade real de que essa informação esteja ligada a outras plataformas. Isso já está acontecendo em outros acessos, como a internet, que permite a convergência. Porém, há um detalhe fundamental que escapa às pessoas: na internet, você tem que ir buscar alguma coisa. Você tem o mundo ali dentro, mas é você, um indivíduo, que está diante da tela. Na tevê, você tem um sinal mandado para todos. Um para todos significa um produto para a sociedade, e a internet quer dizer um indivíduo com todo o acesso permitido a ele, se tiver dinheiro para pagar a banda larga. Pesquisas mostram que a maioria dos acessos à internet é direcionada a portais de busca de outros sites, a programas de bate-papo como o messenger, a sites de relacionamento social ou redes sociais. Isso reforça a importância de uma transmissão que entregue informação pronta para você, desempenhando papel fundamental no dia a dia das pessoas que chegam em casa cansadas e não querem procurar nada, querem assistir a alguma coisa. Então, sempre existirá quem quer assistir e quem quer buscar. São duas ofertas que vão conviver; uma não vai se sobrepor à outra.

C\&E: Qual o impacto social esperado pela introdução dessas mudanças, e como fazê-las chegar à população?

André Barbosa: Acho que a televisão será o grande meio de acesso. Com todas as limitações que a informação a distância ainda tem, a televisão continua sendo fundamental para possibilitar a consolidação da pedagogia escolar mais moderna, com o uso de aparelhos e laboratórios dentro da escola. Imagine, por exemplo, desenvolver com os recursos atuais um projeto nos moldes do TV Escola, que já formou muita gente - eu me lembro inclusive do exemplo do deputado Vicentinho, do PT, que se formou no Ensino Médio por meio de um telecurso. Existem vários exemplos de brasileiros com dificuldades de ir à escola que puderam formar-se através desses programas. Agora podemos somar a eles a interatividade, que traz uma capacidade ainda maior de participação para que essa educação se torne mais completa. E não se limita ao Curso Fundamental; pode-se dar cursos de treinamento, superiores, de pós-graduação. Há uma gama enorme de possibilidades.

Na área da saúde, por exemplo, será possível, como já acontece em alguns países, marcar consultas a distância no Sistema Único de Saúde, escolhendo o médico e o horário pela televisão. Imagine uma senhora de idade no interior do Piauí, que precisa pegar um caminhãozinho para ir à cidade maior e marcar a consulta para depois de três meses. E, quando volta para a consulta, o médico não está lá. Isso acontece no dia a dia. Ela tem dificuldade de ligar a televisão? Não tem. Mas teria com um computador. Esse é outro aspecto da TV que se soma aos dois anteriores, da simultaneidade e da transmissão de informação pronta.

Outro aspecto, que considero fundamental na televisão, na verdade são dois: a credibilidade e a usabilidade. A credibilidade foi conquistada através da garantia de que a televisão traz algo para essa pessoa - seja entretenimento, 
comunicação \& educação • Ano XV • número 3 • set/dez 2010

informação ou educação. A TV é parte da casa. O computador será no futuro, como mostram os nativos digitais, que praticamente já nascem com uma facilidade tremenda de lidar com ele. Mas a maioria da população ainda tem dificuldades com essa usabilidade, assim como com o celular. Com a televisão não tem. E sua usabilidade é uma garantia, também, de uso dos novos apetrechos de educação ou de serviço público. No caso da consulta pública, o usuário pode interagir inclusive por meio de cores, se não souber ler. Existe um aparato de ícones e significantes que permitirão à pessoa, alfabetizada ou não, acionar um determinado tipo de especialista e marcar sua consulta no dia apropriado. A televisão vai dizer "você está escolhendo o dia tal, com o especialista tal". Aí ela vai decidir se quer ou não, escolhendo o vermelho ou o verde, por exemplo.

As universidades estão trabalhando intensamente nesse tipo de oferta de programa interativo: visualizar o imposto de renda pela televisão, acompanhar a Previdência Social, pagar impostos, consultar seu banco, acompanhar campanhas públicas de vacinação, consultar primeiros socorros em caso de urgências médicas. Há uma série de serviços sociais que os japoneses usam para terremotos, por exemplo, e que nós poderemos utilizar para outras coisas. A banda ficará aberta na televisão e você poderá acionar quaisquer informações, bastando procurar o que quer. Há uma série de recursos que a tecnologia permite e que vão facilitar muito a vida das pessoas.

C\&E: Como se desenham as políticas públicas para a chegada dessas tecnologias ao Brasil? Quais as prioridades discutidas?

André Barbosa: Vamos imaginar um triângulo. Cada vértice deste triângulo é uma questão que deve conduzir a política pública para a TV digital, assim como para as outras áreas também. No primeiro vértice está a infraestrutura: é preciso dispor de um meio físico e de uma capilaridade que permita a entrega do produto, ainda mais quando se trata de um sinal simultâneo enviado a todos os lugares. O governo brasileiro pretende construir até 2014 uma estrutura de rede pública fundamental para distribuir o sinal digital das televisões públicas, como a TV do MEC, da Saúde, do Senado, da Câmara, da Justiça e a TV Brasil. São seis instituições que vão utilizar quatro canais, um deles em alta definição e outros três em standard definition ${ }^{2}$. Ao todo serão dezenove programações diferentes sobre temas os mais diversos - saúde, educação, transporte, empregabilidade, segurança, previdência social, bancos. São serviços públicos que já estão na internet - o chamado e-govern - e que agora serão transformados em t-govern. E, evidentemente, vão crescer à medida que as demandas chegarem à casa das pessoas com mais facilidade.

Esse é o primeiro vértice, a infraestrutura. Mas são necessários outros dois grandes aspectos. Um é o desenvolvimento de conteúdos digitais interativos. Hoje, é necessário às escolas de comunicação um novo modelo para a formação do profissional de comunicação, que não mais se dá no nível linear, como nós conhecemos na teoria da comunicação. Hoje ela vai mais longe: tem que ter uma interface com o mundo da computação, do software. Devemos ter um desenvolvedor de programas e um profissional em audiovisual desenhando juntos 
Um novo tempo nas telas brasileiras - Juliana Winkel

a questão interativa. Vai continuar existindo a necessidade de se trabalhar com câmera, cenário, luzes, atores, direção, roteiro. Mas, além da produção da imagem em si, que envolve tudo isso, haverá a superposição de outras informações, requerendo o desenho de um programa ligado à digitalização e à interatividade.

Essa configuração os profissionais ainda não estão preparados para realizar. Atualmente está nas mãos de engenheiros, que não sabem fazer audiovisual. Enquanto isso, nós da comunicação também não sabemos produzir programas. A simbiose é o grande desafio. Mas os conteúdos estão começando a surgir. Já vi, por exemplo, programas de reality show em que o telespectador usa celular, internet e televisão num amálgama que potencializa o modelo desse tipo de produto, destinado a mostrar a intimidade de grupos sociais. Mas pode ser feito com outro conteúdo, utilizando a mesma estrutura. Como realizar, por exemplo, uma aula a distância com uma série de informações disponíveis na tela, permitindo a interatividade e o reconhecimento do aluno? Com uma estrutura que não depende apenas do conhecimento audiovisual, mas também de uma simbiose com softwares. É um desafio muito grande para a universidade, para a educação e para os outros setores da sociedade.

E o terceiro, e também tão importante instrumento, é a questão da base industrial e comercial: oferecer produtos baratos, com baixo custo e financiados à população, ou até subsidiados, para que esse acesso se complete. Então temos a infraestrutura, os conteúdos, que são a informação que se vai entregar, e receberemos isso no aparelho de Set Top Box, nos conversores e nos televisores baratos. Esses três vértices devem caminhar conjuntamente para que se possa oferecer o produto, e são as questões atualmente trabalhadas pelo governo.

C\&E: Quando essas mudanças entrarão efetivamente na vida das pessoas? André Barbosa: A TV Pública deve estar em funcionamento no início de 2011. Acreditamos que canais como São Paulo, Brasília, Belo Horizonte, Rio de Janeiro e Porto Alegre devem se consolidar a partir de janeiro. Depois, nos próximos dois ou três anos, isso deve ser um crescente. Usaremos cada vez mais a tecnologia a distância, seja por telefone, internet ou celular, além da televisão. Não importa qual dos meios será o mais utilizado, mas sim que haverá múltiplos meios à disposição. Mas queremos garantir que um deles seja gratuito, no caso a televisão. Houve muita crítica a essa decisão, alegando-se que as tendências mundiais são a IPTV ou a internet - mas se considerarmos a necessidade e a customização desse investimento em países como o nosso, veremos que não se pode tomar decisões acompanhando o que a Europa ou os Estados Unidos fazem. Por isso a América do Sul, América Central e África optaram por oferecer nosso atual sistema, muito mais próximo da realidade desses países.

C\&E: Quais os principais interesses e objetivos da expansão do programa nacional de banda larga?

André Barbosa: É evidente que, assim como o governo investiu muito na TV digital por entender o papel da televisão neste processo, a banda larga é o futuro, para não dizer o presente, de todo o acesso complexo à pesquisa e à 
comunicação \& educação • Ano XV • número 3 • set/dez 2010

informação. Hoje, qualquer criança pode realizar a pesquisa completa de um trabalho pela internet, sem colar e com um resultado benfeito. Já temos e-books disponíveis em palms, $i$-pads e tudo mais. A tecnologia permite esse acesso com facilidade. Porém, a banda larga ainda é muito cara, lenta e para poucos. Dos $27 \%$ da população com acesso à banda larga, nem $10 \%$ pode se considerar usuário dessa faixa de fato, com oferta de tráfego acima de um megabyte, que permite baixar vídeos, por exemplo. O que o governo quer é oferecer aquilo que a privatização, através das empresas de telefonia, não ofereceu até agora. Quando compraram o direito de oferecer o serviço, as empresas se comprometeram a pôr à disposição um regime de universalidade de serviços a preços módicos, criando o que eles chamam de compartilhamento, para haver concorrência. Mas ainda não fizeram isso. Ao mesmo tempo, todos os países do mundo estão investindo em programas de banda larga, porque sabem da importância desse instrumento para melhorar a qualidade de vida e de educação das pessoas, ao lado de outras plataformas digitais. Então, o governo lançou a decisão: "Ou vocês fazem, ou nós vamos fazer". Agora parece que chegamos ao ponto em que o decreto do presidente terá o apoio das operadoras, o que acho correto. O governo não deveria, do meu ponto de vista, tomar essa tarefa como exclusiva, investindo dinheiro público nisso, já que não será apenas a população a usufruir dessa tecnologia, mas também as empresas. Um acordo no qual elas possam vender a preço barato, distribuindo o acesso pelo Brasil inteiro, já era o objetivo anterior; não precisamos fugir disso.

Dessa forma, o caminho do governo agora será chamar as operadoras e oferecer o que chamamos de backhall, ou seja, o nó físico de uma rede que vai de Fortaleza a Porto Alegre, chamada Rede Eletronet, anteriormente pertencente a uma empresa público-privada que faliu. O governo deverá usar essa rede para transmitir banda larga a preços mais baratos, porém com a ponta da transmissão oferecida por pequenos e grandes provedores. Aí, teremos a livre concorrência. O governo não oferecerá o acesso, pelo menos num primeiro momento, mas vai proporcionar a estrutura que as operadoras já disponibilizam nas suas próprias redes, para que possa exercer o serviço na iniciativa privada.

A grande discussão, por parte das operadoras, é se essa rede vai se tornar uma empresa que oferecerá serviços mais baratos do que ela. Mas isso não é verdade - o governo está acenando, inclusive, para que todos possam discutir a questão tributária e os benefícios dessa estrutura. O objetivo final não é que o governo tenha uma empresa, mas sim que ele também possa oferecer acesso, forçando a concorrência, que até hoje não ocorreu, para que a banda larga seja barata, rápida e acessível a todos.

C\&E: O que podemos dizer sobre o rádio, que já foi tão importante na unidade da comunicação nacional? Ele está acompanhando as mudanças tecnológicas ou deve se restringir a objetivos específicos de comunicação?

André Barbosa: Para mim, o rádio permanece sendo um veículo apaixonante. Fui professor de rádio por muitos anos e escrevi sobre o tema também - o livro Gêneros radiofônicos, que tem inclusive boa circulação entre os estudantes. 
Um novo tempo nas telas brasileiras - Juliana Winkel

Mas, infelizmente, as notícias para o rádio não são das melhores. Não porque o rádio vá morrer, mas porque, apesar de ter sido um veículo exponencial em termos de audiência, hoje passa por sérios problemas. Não consegue sair da faixa dos 4,5\% de investimento publicitário e, portanto, com pouco dinheiro, acaba tendo dificuldades para empregar gente com experiência em locução e produção. A real sobrevivência do rádio não está apenas na melhoria do som, mas em oferecer uma programação que chame a atenção. Se você produz um conteúdo diferente, atraente, tem chances de aumentar a audiência. Mas hoje se investe pouco em roteiro, em novos formatos. O rádio se restringe a notícias e músicas, na maioria dos casos - o que acaba se agravando com a venda das concessões, ou com acordos, para transmissões de proselitismo religioso e discursos diversos. Isso não é universalizar o serviço do rádio.

Acredito que, para que se torne viável economicamente, o rádio digital deve adotar um modelo de negócios acessível à população já ouvinte de rádio, por meio de cursos baratos, programação diferenciada e inteligente, possibilidade de gravar as músicas preferidas e receber outras informações além das que está ouvindo - ou então serviços como o que o americano já pensou, de emissão de bilhetes, pagamentos no banco ou impostos. Todos sabemos que o rádio hoje, ao menos nas grandes metrópoles, é um meio utilizado dentro dos automóveis. As pessoas passam, em média, três ou quatro horas por dia num automóvel, onde não podem ter televisão. O rádio é o grande veículo para isso. Então, se houver valor agregado no instrumento rádio, ele também se fortalecerá. Contudo, é evidente que toda essa revolução tecnológica precisa passar pelo mesmo triângulo da televisão pública: infraestrutura, conteúdos e por equipamentos baratos. Isso, infelizmente, está longe de acontecer: o rádio digital é caro, não tem a mesma cobertura que o rádio analógico e um atraso terrível na transmissão, que vai de 8 a 12 segundos. Imagine você num campo de futebol, ouvindo que o jogador vai bater o escanteio e na sua frente o resultado já aconteceu. Isso não pode ocorrer, principalmente porque o rádio é um veículo urgente, imediato.

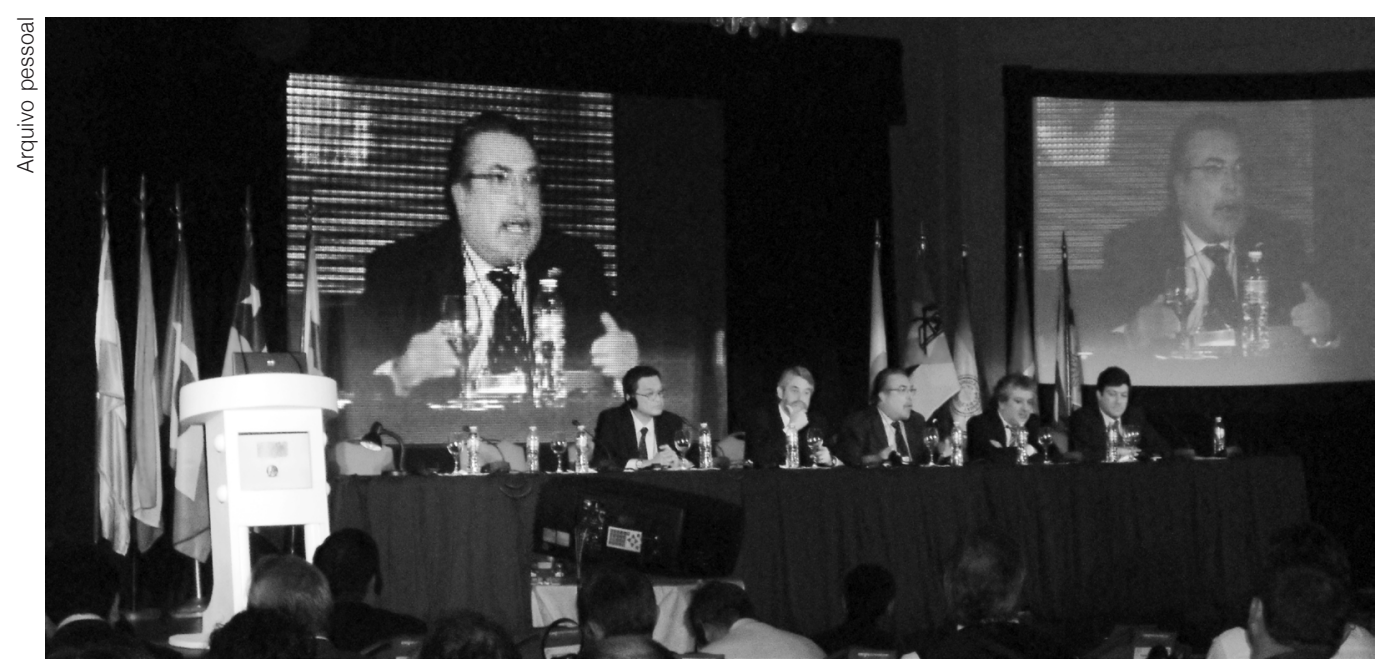

André Barbosa participa da reunião para discutir o ISDB-T (Serviço Integrado de Transmissão Digital Terrestre) Internacional, em Buenos Aires, Argentina, em maio de 2010. 
Ao mesmo tempo, se esses problemas forem contornados, podem se tornar oportunidades para o Brasil, como produto de venda na América Latina, na África e em vários países que precisam e ainda escutam rádio. Voltei da África recentemente e em países como Moçambique, por exemplo, o rádio é o grande veículo. A televisão atinge a $57 \%$ da população apenas, enquanto o rádio chega ao país inteiro. Poderíamos desenvolver um modelo de rádio digital que permitisse esse aspecto de atendimento interativo, oferecendo outros valores além da qualidade de som, com conteúdo diferenciado e custo baixo - porque senão as pessoas não vão deixar de comprar o seu computador ou mesmo sua televisão portátil para comprar um rádio digital cujo serviço é igual ao do outro rádio. Nos Estados Unidos, por exemplo, onde existe a maior oferta de rádio no mundo, temos aproximadamente 13 mil emissoras. A digitalização, porém, alcançou somente 1.500 rádios dessa totalidade, porque as pessoas não veem vantagem em trocar seu rádio analógico que já presta serviço, é barato, tem um bom som de FM, pega no país inteiro, entra em rede, tem notícia, música e informação. Não veem razão para investir num radinho digital de 400, 300, 100 dólares, ou mesmo 40 dólares.

A única saída para o rádio digital seria um trabalho de convergência com as outras mídias e o oferecimento, principalmente, de serviços de valor agregado - o que não é exatamente fazer rádio ou melhorar a linguagem radiofônica, que é o que nós gostaríamos que acontecesse. Mas temos de lutar para que isso mude, porque é o veículo mais popular de todos, daí a simpatia de todos por ele.

O que percebo é que, de modo geral dentro da comunicação, muitas vezes o aspecto social da informação é minimizado em prol do entretenimento. $\mathrm{O}$ entretenimento é fundamental: sem alegria, sem felicidade, não se vai para a frente. Mas acho que podemos usar o entretenimento a favor de projetos sociais no rádio e na televisão, que são veículos de massa e que permanecerão por muito tempo assim para 4,5 milhões de pessoas, nesses países dos quais estamos falando. É vital para esses países a possibilidade de entrar no mundo digital através da TV interativa e do rádio interativo, no aguardo de projetos de banda larga mais efetivos. 